\title{
Importance of Life Cycle Analysis of the Printed Circuit Board Computer
}

\author{
Miguel Aguilar Cortes', Martha L. Domínguez Patiño ${ }^{2}$, Nadia Lara Ruíz ${ }^{1}$, Luz E. Marín Vaca1 \\ ${ }^{1}$ Graduate Engineering and Applied Science, Universidad Autónoma del Estado de Morelos, Cuernavaca, \\ Morelos, México \\ ${ }^{2}$ Faculty of Chemical and Engineering Sciences, Universidad Autónoma del Estado de Morelos, Cuernavaca, \\ Morelos, México \\ Email: maguilarc@uaem.mx
}

Received 27 November 2015; accepted 17 January 2016; published 20 January 2016

Copyright (C) 2016 by authors and Scientific Research Publishing Inc.

This work is licensed under the Creative Commons Attribution International License (CC BY). http://creativecommons.org/licenses/by/4.0/

(c) (i) Open Access

\begin{abstract}
It is estimated that there is a generation of 307,224 ton/year [1] of waste from electronic and electronic equipment (WEEE) in Mexico, of which $10 \%$ is recycled, $40 \%$ remains stored and $50 \%$ reaches landfills or uncontrolled dumps. In the practice, even the regulatory instruments are not consolidated and the adequate management of the use of WEEE management, so the aim of this study is an analysis of life cycle of printed circuit boards (TCI) to identify the management alternatives that represent the least impact to the environment. This assessment was carried out using software SIMAPRO to determine the environmental impact of each scenario, through the comparison of impacts and the proposed improvements to reduce it, following phases of this methodology by applying standards, ISO 14040/ISO 14044 [2], using data from the INE official reports since 2006 until 2010 which concentrate the information of the WEEE problem in Mexico. These data were pooled to carry out inventories according to the availability in the information, identifying the environmental impacts generated by processing. The conclusions of the LCA will serve to identify the stage with greater environmental impact, and thus propose ideas for improvement in order to minimize this impact.
\end{abstract}

\section{Keywords}

Analysis of Cycle of Life, Environmental Impact, Electrical and Electronic Equipment, End of Life, Printed Circuit Card

\section{Introduction}

In recent years, growth in the sector of electrical and electronic equipment has been spectacular, since its prod-

How to cite this paper: Cortes, M.A., Patiño, M.L.D., Ruíz, N.L. and Vaca, L.E.M. (2016) Importance of Life Cycle Analysis of the Printed Circuit Board Computer. Open Journal of Applied Sciences, 6, 1-6.

http://dx.doi.org/10.4236/ojapps.2016.61001 
ucts that have a very short economic life cycle and a rapid obsolescence [3]. Parallel to the growth of this sector, it has been increased the volume of its waste, by the high demand for electronic products, particularly computers and mobile phones; these equipment's innovation cycles become increasingly shorter and its replacement is accelerated, generating an increase of electronic waste, which makes them potentially hazardous waste against improper disposal and the presence of toxic compounds in its structure, processes and high impact to the environment.

Life cycle analysis is a key methodology for the definition of Government and business strategies in the context of the prevention of pollution. Its systematic character allows you to interpret the environmental performance in an integrated manner, taking all environmental impacts during the life cycle [4]. The benefit of the application of the methodology of life cycle analysis is shown in the definition of preventive strategies for greater efficiency and the effect of learning to understand the relationships between the different elements and processes of each stage of the life cycle of the product in your environment.

Projections indicate that in Mexico to the year 2025 they could be generated between 80,000 and 140,000 tons of waste from computers and peripherals, if it is not advanced in its collection and environmentally sound management.

Regulations not only prompted consideration of the recycling in the product design. A side effect is also still emphasized the importance of considering systematically the environmental impact throughout the product life cycle.

To be able to design a product with low environmental impact, first we need to know the potential effects that product will have on the environment, throughout its life, in order to have an impact on those who pose a greater impact. Therefore, you can use the tool of analysis of the cycle of life (LCA), which allows you to make an inventory of the environmental impacts associated with the products and/or services, evaluate them and generate a series of opportunities to improve the situation-diagnosed [5].

This technique examines each stage in the life cycle, from the extraction of raw materials to manufacturing, distribution, use, possible recycling and final disposal of the product, making an inventory of inputs and outputs from the environment to the system analysed and vice versa. Additionally, perform analysis of the life cycle in products or alternative services allows comparing their environmental impacts [6]. LCA can serve as a support, in this way, to the redesign of products, to reduce their pollution.

Research presents the results of the application of the technique of life cycle assessment using the software SIMAPRO to TCI computer, in order to determine which stage of the life cycle contributes less impact to the environment and help to know ways suitable for the management of WEEE.

\section{Methodology}

There are various aspects and methodologies to assess the life cycle assessment of electronic waste at the end of its useful life, this work was the structure proposed by the ISO 14040 standard using as a functional unit TCI.

We did a search for information so were inventories of electronic waste generation by analyzing the information in official reports whereas the work carried out by INE from 2006 until 2010 and that concentrated the problem of WEEE information in Mexico. These data were pooled to carry out inventories of generation based on availability information.

Life cycle analysis includes the analysis of the inventory and evaluation of the impact of life cycle. This methodology allows to identify and evaluate the environmental burdens associated with the life cycle of materials and services throughout its production process, "from the cradle to the grave" and allows identification and evaluation to minimize the environmental consequences of the use of natural resources and environmental burdens, through the use of inventories themselves and bibliographic databases where it is scanned and bought the environmental aspects of a product in a systematic manner, following the recommendations of the regulation UNEEN-ISO 14040:2006.

\section{Objective Analysis}

The aim of this work is the analysis to identify the environmental impact LCA along a TCI, a desktop computer model COMPAC 550. After identifying, assessing and quantifying the different impacts generated during LCA, a report will be obtained for decision-making on the variables involved in the manufacturing process and the selection of materials and options for managing the end of life. 
Similarly, the analysis aims to verify whether it meets the requirements of the current legislation on waste EEE, because the TCI computer is a piece of equipment that is included in one of the categories set out in WEEE.

Finally different scenarios of use and end of life management referred to draw conclusions in order to make optimum use of the product, from the environmental point of view.

\section{Considerations}

Were considered for the analysis of end of life, computers discharged from the Academic Computer Center (ACC) of the Faculty of Chemical Sciences and Engineering (FCQeI) of the Universidad Autónomadel Estado de Morelos (UAEM).

For this analysis, it is considered that the equipment reaches the end of its useful life over a period of five years, at the time this is written off and remains obsolete equipment. To do this we consider two alternative scenarios:

> Current rating: This scenario corresponds to the process currently followed by the teams at the end of its useful life, according to the mechanisms within the UAEM.

$>$ Complete Recovery: This scenario is considered a $100 \%$ recovery of the residue, and therefore there is no fraction landfill.

The team works 12 continuous hours on weekdays and six hours on Saturday.

With regard to energy consumption, which will be different depending on whether the computer is running, it is in use by users, or in sleep or off but connected to the mains.

Consumption, depending on whether the computer is in use, at rest or off is in Table 1.

Given the statistics of the data and use above teams FCQeI CCA, power consumption of the equipment is in Table 2.

For the analysis of the end of life, has chosen a physical functional unit: where the inputs and outputs are related to a single product inventory. However, in order to draw conclusions with respect to variations in the end of life, it is considered different scenarios for both use and end of life as it is analyzed by a sensitivity analysis. Scenarios for use, it should be noted that this functional unit is essentially unchanged. By comparing the results, we will consider this phenomenon.

\section{Results}

In terms of energy consumption, will be different depending on whether the device is operating, is in use by users, or in standby or turned off but connected to the mains.

Consumption, depending on whether the computer is on, in sleep or off is in Table 1.

The evaluation of environmental impact of the ACV, show the result set of indicators called profile of the impact assessment and provide information on environmental variables associated with the inputs and outputs for each of the analyzed equipment, systems, there are six possible impact assessments, which are encoded as shown in Table 3.

In order to determine in which stage of the life cycle takes place these impacts are analyzed individually the two categories. Figure 1 shows the impacts along the life cycle and the decrease in the reserves of the ecological landscape units.

In order to analyze the variability of the results according to different scenarios, we have performed a sensitivity analysis. Of all the possible scenarios are described in detail only those corresponding to MA MB vs MB vs $\mathrm{HB}$ as representative of the rest.

The influence of the end of the life in MA Management vs MB is shown in Figure 2, for each phase of the life cycle and the variation in the results to change the scenario.

As in the previous chart done a sensitivity analysis by varying the usage scenario, the results are shown in Figure 3 .

\section{Discussion of Results}

According to the results can be seen as the change in the disposal or revaluation of electronic waste has a different related environmental impact; however, we can see that more far-reaching (35\%) electronic waste recycling options provide benefits that should be considered [7]. Duan and collaborators found that recycling was one of the best activities because of their potential to reuse materials and replacing virgin raw materials; also, the impacts of the reuse or recycling are smaller than extractive industry. 
Table 1. Energy consumption [own elaboration].

\begin{tabular}{cccc}
\hline $\begin{array}{c}\text { COMPAQ COMPUTER MOD. } \\
550\end{array}$ & USE & MODE & OFF \\
\cline { 2 - 4 } & $10 \mathrm{Kwh}$ & $5 \mathrm{Kwh}$ & $1 \mathrm{Kwh}$ \\
\hline
\end{tabular}

Table 2. Power consumption of MFP [own elaboration].

\begin{tabular}{ccccc}
\hline & \multicolumn{3}{c}{ USER } \\
Time (day) & OFF & LOW & MEDIUM & HIGH \\
\cline { 2 - 5 } Shelf life (h) & 48,000 & 48,000 & 48,000 & 48,000 \\
User (h) & 0 & 4 & 8 & 12 \\
Repose (h) & 0 & 8 & 4 & 12 \\
Off (h) & 24 & 12 & 112 & 132 \\
\hline
\end{tabular}

Table 3. Scenarios considered in the case study.

\begin{tabular}{cccc}
\hline SCENARIOS & & CONSUMPTION \\
\cline { 2 - 4 } & LOW (B) & MEDIUM (M) & MA \\
\hline Valorization current (A) & LA & MB & HA \\
\hline valorization complete (B) & LB & HB \\
\hline
\end{tabular}

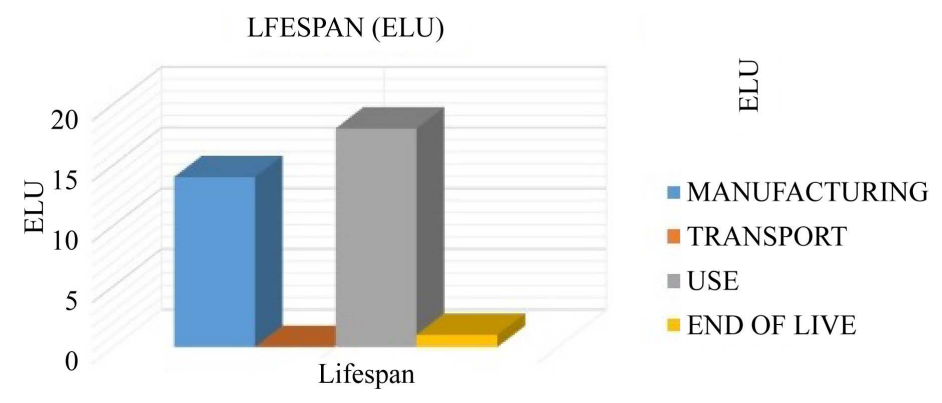

Figure 1. Life expectancy (ELU) on the LCA.

On the other hand any recycling process, especially of inadequately or rustic processes such as those used in developing countries, generate emissions and likely adverse effects to the environment [8], by found in this study, we can see that the impacts are less than those found if electronic waste have as final destination of landfills or open-pit landfills, being this last option, the largest impacts, both regional as to health.

Analysis of life cycle of electronic waste carried out, have data of the current situation in Mexico, so many of the electronic waste recycling processes can be improved and the tendency to generate emissions may also decrease, which long ago most promising alternative recycling of electronic waste, since in it we can find better ways to control and containment of emissions than in landfills to heaven open and even the current controls on landfills of Mexico [9]. It is important to mention that one of the biggest regional impacts that we observed in this project, was for the use of transport motor with fossil fuels, which cause pollution in the air and is one of the gases that cause the greenhouse effect, while in other studies [9] have found that the effects of transport are not so relevant, although these studies contemplate throughout the lifecycle, from manufacturing to disposal, while the present work is focusing on the stage of "end of life", which causes that this activity may have a greater impact to be taken into account when the related environmental policies are designed. 


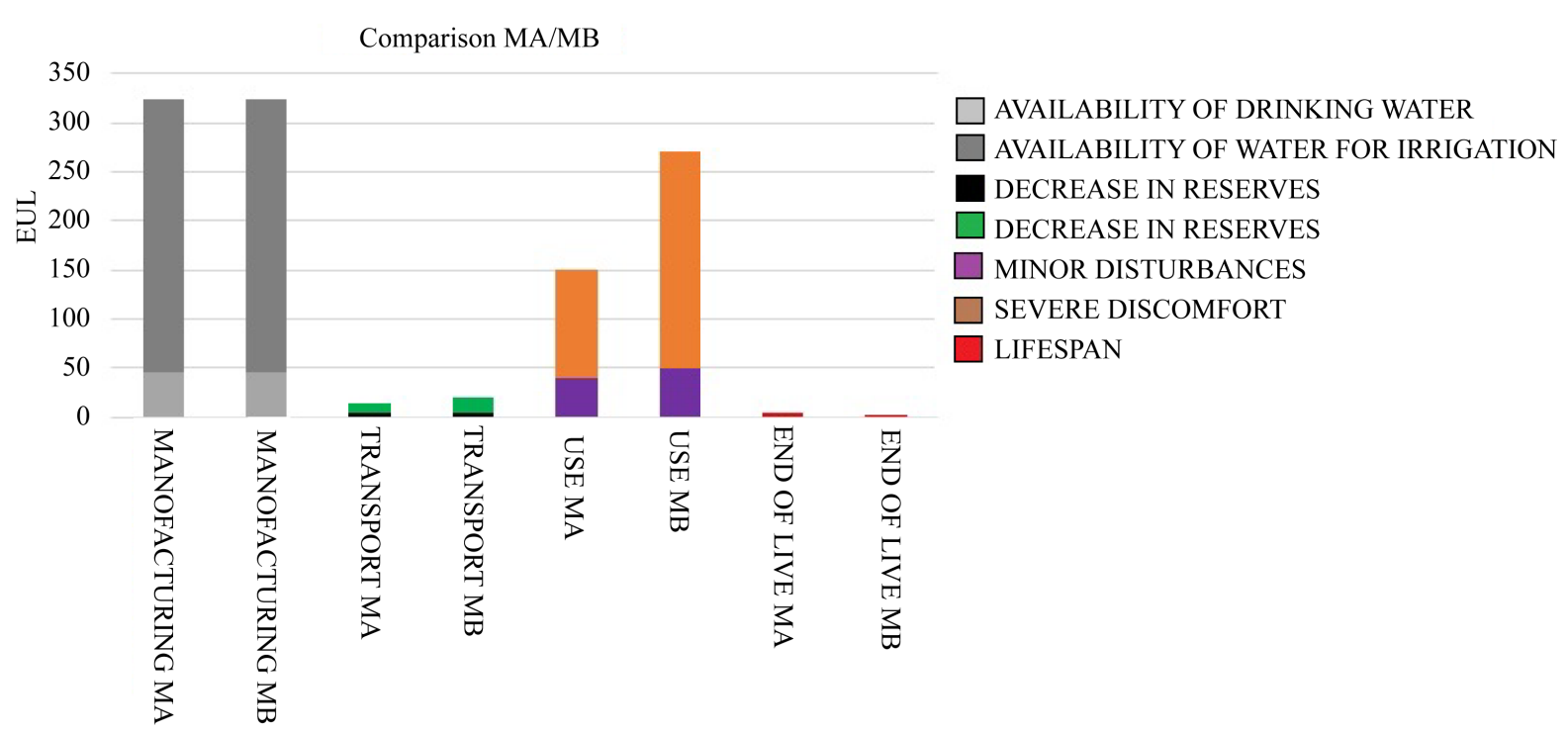

Figure 2. Influence of end of life management. Comparison: LCA MA vs MB.

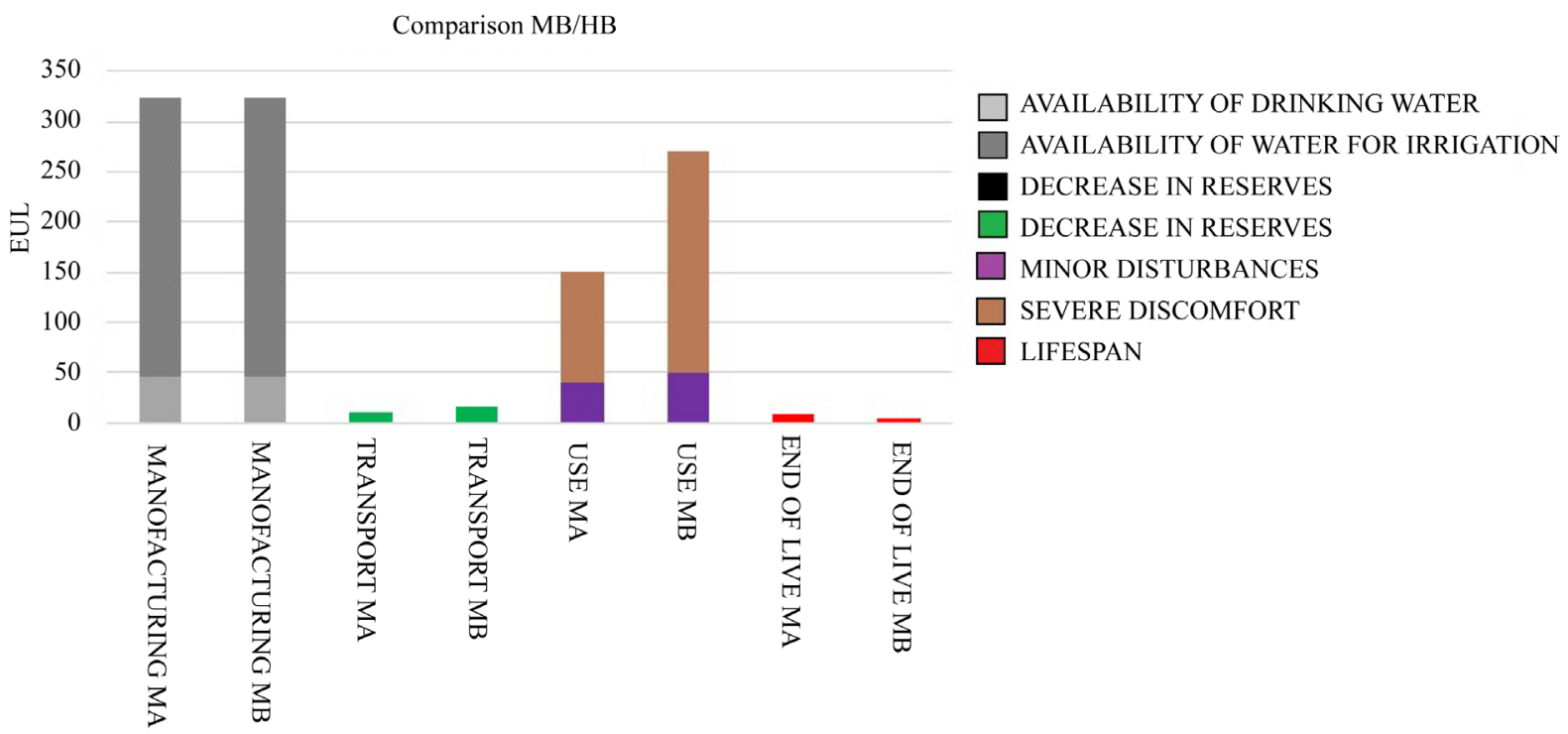

Figure 3. Influence of the intensity of use. Comparison: MB vs HB.

Finally, it is important to mention that the nature of each electronic product has a specific dynamic but as a whole they tend to decrease their times of life [2] [7], which might endanger the construction of alternatives, if it fails to specify in an environmental policy in Mexico.

These electronic products tend to shorten your time of life, most of the time by the habits of consumption. Therefore, it is important to translate some studies in alternative disposal and recycling real that find echo in the decision-makers and take practice [10]; otherwise, it is possible that steepens the problem.

\section{Conclusions}

After conducting this analysis of ACL, it is concluded that:

High-energy consumption, as well as a high degree of liberation of heat and gases to the atmosphere, occurs during the processing of materials. These could be used by energy recovery, thus reducing the negative effects of both in the environment and thus reducing the greenhouse effect.

The assembly does not represent a high impact in the LCA of the TCI, but can be substantially improved if 
the parts that make up these enclosed systems to facilitate mounting and dismounting. This mode will be facilitated the final treatment of the product, to make viable strategies such as reuse or the remanufacturing.

Electronic waste recycling alternatives have lower environmental impacts; this shows us that, in the case of electronic waste, the best alternative is aimed to develop the recycling industry in Mexico with the suppression of landfills to open in the first instance, and in a second stage the development of environmental policies that eliminate electronic waste from landfills also.

Electronic waste is the source of resources that should be exploited and revalued, not leaving out a policy of environmental and labour protection. As yielding materials range from metals such as lead, tin or copper to contained precious metals (gold, silver, palladium) [11], allowing the development of an important industry that drives the creation of infrastructure and management of plastics with retarding of flame in these wastes.

On the other hand, the stage of great environmental impact is used. As we have seen, this depends in great part of the end user of the product and the good use that it makes [12]. Such devices consume energy even in the moments that are not in use but if connected to the network. Therefore, it is recommended users disconnected from the network if it will not be used. Regarding manufacturers, they consider the inclusion of a switch disconnector of the team. This technology is becoming more widespread in monitors and power supplies.

\section{References}

[1] INE (2012) Guía municipal de gestión integral de residuos de aparatos eléctricos y electrónicos, para el noreste de México.

[2] AENOR (1998) UNE-EN ISO 14040:1997. Environmental Step. Analysis of the Life Cycle: Beginnings and Structure. AENOR, Madrid.

[3] (2007) INE (Diagnostico Regional sobre la Generación de Residuos Electrónicos al final de su vida útil en la región noreste de México).

[4] La responsabilidad extendida del productor en el contexto latinoamericano. Informe de Greenpeace, Argentina, 20 de octubre 2008. http://www.greenpeace.org/argentina/es/informes/la-responsabilidadextendida-d/

[5] Directiva 2002/96/CE del Parlamento Europeo y del Consejo, sobre residuos de aparatos eléctricos y electrónicos, RAEE/WEEE (27 de enero de 2003).

[6] INE (2008) Diagnóstico Regional sobre la generación de Residuos Electrónicos al final de su vida útil en la Región Noreste de México.

[7] ECORAEE. Informe del proceso de reutilización de los RAEE dirigido a proponer políticas de reglamentación de conformidad con la legislación comunitaria (31/12/13).

[8] Kang, H.-Y. and Schoenung, J.M. (2005) Electronic Waste Recycling: A Review of US Infrastructure and Technology Options. Resources, Conservation and Recycling, 45, 368-400. http://dx.doi.org/10.1016/j.resconrec.2005.06.001

[9] Directiva 2002/96/CE del Parlamento Europeo y del Consejo, sobre residuos de aparatos eléctricos yelectrónicos, RAEE/WEEE (27 de enero de 2003).

http://www.relec.es/relec/images/stories/GestionRAEEs/NOTICIASRELECBOLETIN16.pdf

[10] Directiva 2002/95/CE-RoHS (Restriction of Hazardous Substances-Restriccion de Uso de Substancias Peligrosas), Parlamento Europeo/Consejo de la Unión Europea. http://eurlex.europa.eu/LexUriServ/LexUriServ.do?uri=OJ:L:2003:037:0019:0023:es:PDF

[11] Jha, M.K., Lee, J.-C., Kumari, A., Choubey, P.K., Kumar, V. and Jeong, J. (2011) Pressure Leaching of Metals from Waste Printed Circuit Boards Using Sulfuric Acid. JOM, 63, 29-32. http://dx.doi.org/10.1007/s11837-011-0133-z

[12] ASIMELEC (2005) Working Day on Electric and Electronic Apparatuses and the Step of His Residues, Valencia, Electric Tecnología’s Instituto. 